\title{
REVIEW
}

\section{Frontier in hair loss and trichoscopy: A review}

\section{Ebtisam Elghblawi}

Dermatology OPD, St. James Hospital Group, Tripoli, Libya

\begin{abstract}
Skin surfaces have always been examined using dermoscopy, a familiar tool which is useful to magnify and examine skin especially in cases of pigmented skin lesions. However, to examine the hair and scalp, a practical tool called trichoscopy has surfaced recently and has proven to be handy and functional in diagnosing most hair-related diseases. It is also referred to as dermoscopy of the hair and the scalp. It can aid in assessing active diseases in the scalp and hair, such as yellow dots, dystrophic hairs, cadaverized black dots, white dots, and exclamation mark hairs all of which denote specific criteria for hair diseases. Trichoscopy is a very newly developed non-invasive technique for hair image analysis. It permits non-invasive visualization of hair shafts at higher intensification (about $\times 70$ and $\times 100)$ and enables measurement of hair shaft width without the need for removing hair for diagnostic reasons. Moreover, it helps in vivo visualization of the epidermal portion of hair follicles and perifollicular epidermis (orifices). Consequently, it is valuable as it permits the inspection of structures that are otherwise not seen by the naked eye. Trichoscopy is the new frontier for the diagnosis of hair and scalp disease. Nowadays, a trichoscope is considered a must for dermatologists and it is a hot topic in the treatment of hair diseases. There is pooled evidence that the utilization of trichoscopy in the clinical setting for evaluating hair disorders can improve its diagnostic capability beyond simple clinical scrutiny. Trichoscopy can identify both hair shaft and hair opening abnormalities without the need for hair sampling, as well as distinguish between different scalp and hair diseases. Furthermore, it can give easy and quick evaluation of the hair with a follow-up to determine progress and prognosis of the disease with photos. It can also aid in some genetic hair shaft dystrophies such as trichorrhexis nodosa, trichorrhexis invaginata, monilethrix, pili annulati, and pili torti. The limitation of trichoscopy is that it needs prior knowledge to apply it effectively in order to mandate an efficient use by correctly interpreting the findings and their significance. In cases where there are unsettled discrepancies, a histopathological investigation is needed. The interest in trichoscopy has vastly increased and has become an indispensable tool in evaluating patients with hair loss. The aim of this review is to supplement existing knowledge on trichoscopy with recent readings of different scalp and hair conditions that are commonly encountered in clinical settings.
\end{abstract}

Keywords: Hair loss; alopecia; non-cicatricial hair loss; cicatricial hair loss; diagnosis; dermoscopy; scalp dermoscopy; hair; anisotrichosis; trichoscopy

Citation: Elghblawi E. Frontier in hair loss and trichoscopy: A review. J Surg Dermatol 2016; 1(2): 80-96; http://dx.doi.org/10.18282/jsd.v1.i2.8.

Correspondence to: Ebtisam Elghblawi, Dermatology OPD, St. James Hospital Group, Tripoli, P.O. Box 3232, Libya, ebtisamya@yahoo.com

Received: $9^{\text {th }}$ December 2015; Accepted: $18^{\text {th }}$ January 2016; Published Online: $25^{\text {th }}$ July 2016

Copyright @ 2016 Elghblawi E. This is an Open Access article distributed under the terms of the Creative Commons Attribution-Non Commercial 4.0 International License (http://creativecommons.org/licenses/by-nc/4.0/), permitting all non-commercial use, distribution, and reproduction in any medium, provided the original work is properly cited. 


\section{Introduction}

Normal terminal hair is uniform in its thickness and color throughout the length (Figure 1). The width of normal hair is usually more than $55 \mathrm{~mm}$. Terminal hairs may have medullae that are continuous, interrupted, fragmented or absent (Figure 2). Up to $10 \%$ of normal human scalp hair is made up of vellus hairs which lack the medulla ${ }^{[1]}$. Trichoscopy of normal scalp illustrates follicular units composing of 2-4 terminal hairs and 1-2 vellus hairs ${ }^{[1,2]}$.

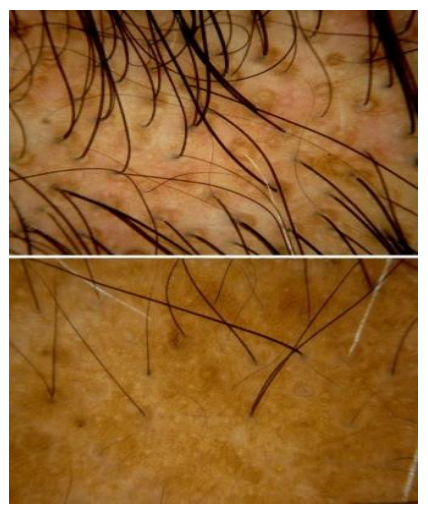

Figure 1. Normal scalp and hair

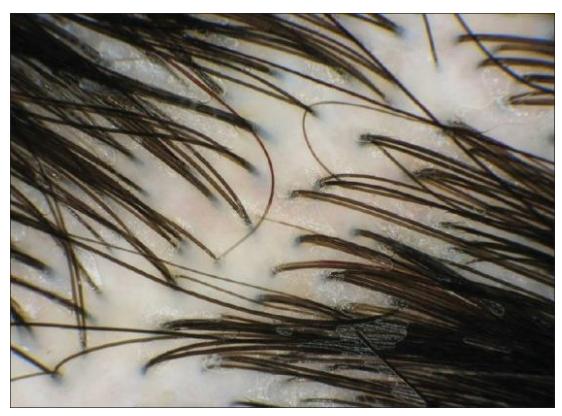

Figure 2. No diversity of hair shaft diameter ${ }^{[1,2]}$

There are many hair-related diseases of the scalp which reflect how they affect the hair. Most dermatological clinics are crowded with complaints related to hair loss, mostly from women. With the progress of hair loss over time, it may become cosmetically unacceptable and psychologically frustrating to patients. Losing hair is not usually a health-threatening condition. Nevertheless, it can affect a patient's self-esteem by inflicting enormous psychological and emotional distress. Trichoscopy aids in visualizing hair at working magnifications of 20-fold to 70 -fold and up to 160 -fold ${ }^{[2-7]}$.

Trichoscopy has recently aid in rapid diagnosis of some genetic hair shaft dystrophies, namely trichorrhexis nodosa, trichorrhexis invaginata, monilethrix, pili annu- lati, and pili torti, in addition to pediatric patchy scalp hair loss conditions such as tenia capitis and aleopecia areata, as these show specific trichoscopic features ${ }^{[5-7]}$ that necessitate immediate medication rather than awaiting cultures which would take days to reveal results (Table 1, Diagram 1). Trichoscopy is a rapid, simple, valuable, and non-invasive effective tool, saving time and money to reach a precise diagnosis and proposes immediate treatment ${ }^{[5,8-10]}$.

Furthermore, trichoscopy is a novel, sensitive, and underutilized means which facilitates the visualization of the surface and constitutes color outlines of scalp and hair ${ }^{[9,10]}$. It provides rapid detection of scalp and hair disorders with advanced diagnostic accuracy, predicts the course of the disease, and decreases the unnecessary need for biopsies. It can generally alienate hair signs, vascular patterns, pigment patterns, and interfollicular patterns, all of which can denote specific diseases and aid in making proper diagnoses ${ }^{[6-8]}$.

Recently, its tasks were stretched out to assist in diagnosing some inflammatory scalp conditions such as lichen planopilaris (LPP), scalp psoriasis, and discoid lupus erythematosus (DLE). Trichoscopy can help differentiate between different categories of hair loss, namely cicatricial and non-cicatricial alopecias and hair shaft disorders where trichoscopic examinations and findings are distinctive. In addition, trichoscopy will avoid unnecessary invasive scalp biopsies. However, if a biopsy is mandatory, trichoscopy can aid in assessing the active biopsy sites following hair and scalp disorders ${ }^{[1-6]}$.

\section{Chief applications of trischoscopy}

The main clinical classifications, as well as trichoscopic findings and recognitions, were presented in Tables $\mathbf{1}$ and 2, Diagram 2, and Chart 1.

Non-cicatricial alopecias: Female pattern hair loss (FPHL), telogen effluvium (TE), androgenetic alopecia (AGA), alopecia areata (AA), alopecia areata incognita (AAI), scalp psoriasis and seborrheic dermatitis, tinea capitis (TC), trichotillomania (TTM), traction alopecia, temporal triangular alopecia (TTA), and syphilitic alopecia.

Cicatricial alopecias: LPP, DLE, frontal fibrosing alopecia (FFA), folliculitis decalvans (FD), tufted folliculitis (TF), dissecting cellulitis (DC), and Pseudopelade of Brocq (PPB).

The main genetic hair shafts disorders with their main trichosopic readings are as shown in Diagram 1: Trichorrhexis nodosa (brush fractures), trichorrhexis invaginata (shafts nodes), monilethrix (beaded shaft), pili annulati (ringed hair), and pili torti (twisted shafts). 
Table 1. Summary of trichoscopic findings and readings about Alopecia

Non-cicatricial alopecia
Presence of empty follicular openings is a common trichoscopy find-
ing.

Female pattern hair loss (FPHL)

The presence of hair with different caliber is typical of FPHL and reflects progressive hair miniaturization due to the disease.

\section{Telogen effluvium (TE)}

Presence of empty hair follicles over entire scalp, one follicular hair unit dominance and perifollicular discoloration (perpilar sign), and upright short hair regrowth.

\section{Androgenetic alopecia (AGA)}

Hair shaft thickness heterogeneity, multiple thin and vellus hairs, peripilar halo, YD, perifollicular discoloration, and predominance of follicular units with only one hair. These features predominate in the frontal area. Sebaceous gland hypertrophy.

\section{Alopecia areata (AA)}

Uniform black dots (BD) and micro-exclamation mark hairs and tapered hairs correlate with disease activity, whereas YD and vellus hairs correlate with disease severity.

\section{Alopecia Areata Incognita (AAI)}

Numerous diffuse YD of different size and uniform colors within the follicular orifices of both empty and hair-bearing with a large number of re-growing of tapered terminal hairs in the entire scalp

Scalp psoriasis

Regularly distributed twisted and lacelike blood vessels.

Seborroic dermatitis

Thin arborizing vessels may be observed.

\section{Tinea capitis (TC)}

Comma shaped, zigzag, corkscrew hairs, BD, and short broken hairs Zigzag shaped hairs are the diagnostic trichoscopic features of tinea capitis.

\section{Trichotillomania (TTM)}

Trichoptilosis "longitudinal split ends" and irregular coiled hairs, hair shafts of variable length, coiled fractured hair shafts. Additionally some other findings, BD, flame hair, V-sign, follicular hemorrhages, tulip hair, and hair powder.

Traction alopecia

It shares some features of TMM with some hair casts, WD lacking follicular opening, hair thinning, and decreased hair density.

Temporal triangular alopecia (TTA)

Normal follicle orifices with vellus hair surrounded by terminal hair.

Syphilitic alopecia

$\mathrm{BD}$, focal atrichia, hypopigmentation of hair shaft, empty ostia of hair follicle, and YD.

\section{Cicatricial alopecia}

Trichoscopy shows milky-red or ivory-white areas lacking follicular openings in all forms.

\section{Lichen planopilaris (LPP)}

Shows perifollicular inflammation (spare intervening follicles), tubular perifollicular scaling, elongated, concentric blood vessels, and "classic white dots (WD)", which merge to form white areas.

\section{Discoid lupus erythematosus (DLE)}

Atrophy, complete follicle paucity, scattered dark-brown discoloration of the skin, large hyperkeratotic folliculilar yellow dots (YD) and thick large arborizing vessels, and follicular red dots.

\section{Frontal fibrosing alopecia (FFA)}

Mild perifollicular scaling, absence of follicular opening, follicular hyperkeratosis, follicular plugs, and erythema.

\section{Folliculitis decalvans (FD) and tufted folliculitis (TF)}

Tufted hairs (polytrichia), perifollicular erythema, large follicular pustules with emerging hair shafts and perifollicular starburst pattern hyperplasia (doll hair).

\section{Dissecting cellulitis (DC)}

"3D" YD imposed over dystrophic hairs, large, yellow amorphous areas, and pinpoint WD with a whitish halo.

\section{Pseudopelade of Brocq}

Nonspecific. It is as white areas with no follicular openings. Also some solitary dystrophic hairs can be seen at the periphery of the lesion.

\section{Non-cicatricial alopecias}

\section{Female pattern hair loss}

It is usually present with visible patterns of hair loss, thus making a bedside diagnosis likely doable ${ }^{[11-13]}$.

Trichoscopic findings: According to Bhamla et al., the presence of hair at different statures is typical of FPHL and reflects progressive hair miniaturization due to the disease (about $75 \%$ anisotrichosis on trichoscopy) ${ }^{[12]}$. The presence of more than six vellus hairs in the frontal scalp at 20-fold magnification can be used as an additional criterion of FPHL (Figure 3) ${ }^{[5]}$.

\section{Telogen effluvium}

It is a self-limiting, abrupt diffuse hair loss (on the entire scalp) and thinning process with premature development 

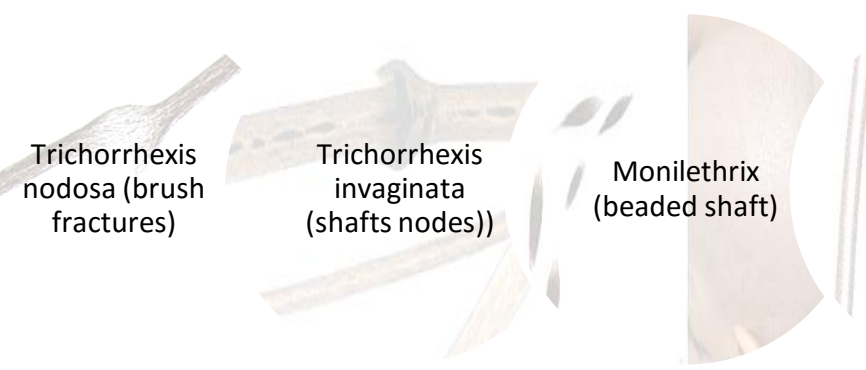

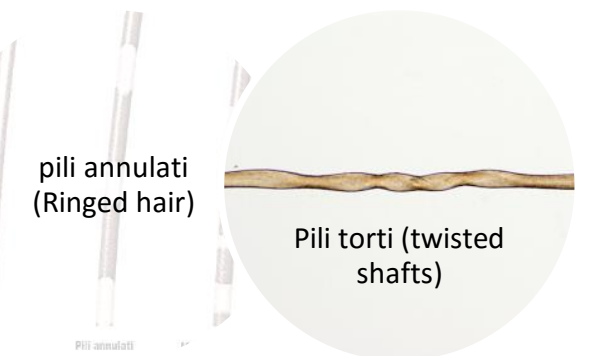

Diagram 1. Genetic hair shafts dystrophies and the main trichoscopic findings

Table 2. Summary of main different dots

\begin{tabular}{|c|c|c|c|}
\hline Dots type & Indication & Implication & Marker \\
\hline YD & $\begin{array}{l}\text { Sensitive feature of AA, but are also seen in some } \\
\text { cases of AGA and alopecia incognita (AAI). YD } \\
\text { in AA are keratinous whereas they represent se- } \\
\text { baceous debris in AGA. }\end{array}$ & $\begin{array}{l}\text { Embody follicular infundibu- } \\
\text { lum, distended with degenerat- } \\
\text { ing keratotic, keratinocytes and } \\
\text { sebum vary in color, shape, and } \\
\text { size. }\end{array}$ & $\begin{array}{l}\text { Known to be the marker of AGA and } \\
\text { AA. }\end{array}$ \\
\hline $\begin{array}{l}\text { BD i.e. } \\
\text { Cadaverized } \\
\text { dots }\end{array}$ & $\begin{array}{l}\text { These are seen within the YD and represent stubs } \\
\text { of hair that are fractured before emergence from } \\
\text { the scalp in AA. }\end{array}$ & $\begin{array}{l}\text { Broken pigmented hairs at scalp } \\
\text { surface }\end{array}$ & \\
\hline WD & $\begin{array}{l}\text { Pale WD are seen in cicatricial alopecias that } \\
\text { spare the interfollicular epidermis, like LPP or } \\
\text { folliculitis decalvans. }\end{array}$ & $\begin{array}{l}\text { Represent the destroyed follicles } \\
\text { that are replaced by fibrous } \\
\text { tracts }\end{array}$ & $\begin{array}{l}\text { Can be fibrotic dot or pinpoint WD. } \\
\text { The classic big, irregular perifollicular } \\
\text { seen in LPP. Pinpoint WD are small, } \\
\text { regular with peripheral pigmentation } \\
\text { which means empty follicle or eccrine } \\
\text { sweat gland opening that can be seen } \\
\text { in sun exposed areas in dark skin. }\end{array}$ \\
\hline $\begin{array}{l}\text { Red dots and } \\
\text { globules (RDG) }\end{array}$ & RDG are the key diagnostic criterion for psoriasis. & $\begin{array}{l}\text { Dilated infundibula containing } \\
\text { keratotic material and reduction } \\
\text { in number and size of sebaceous } \\
\text { glands with presence of dilated } \\
\text { vessels and red blood cells ex- } \\
\text { travasation in perifollicular } \\
\text { distribution }\end{array}$ & Seen in DLE and vitiligo. \\
\hline Pink/grey & Prognostic indicator for eyebrow regrowth & & Seen on eyebrows of FFA. \\
\hline
\end{tabular}

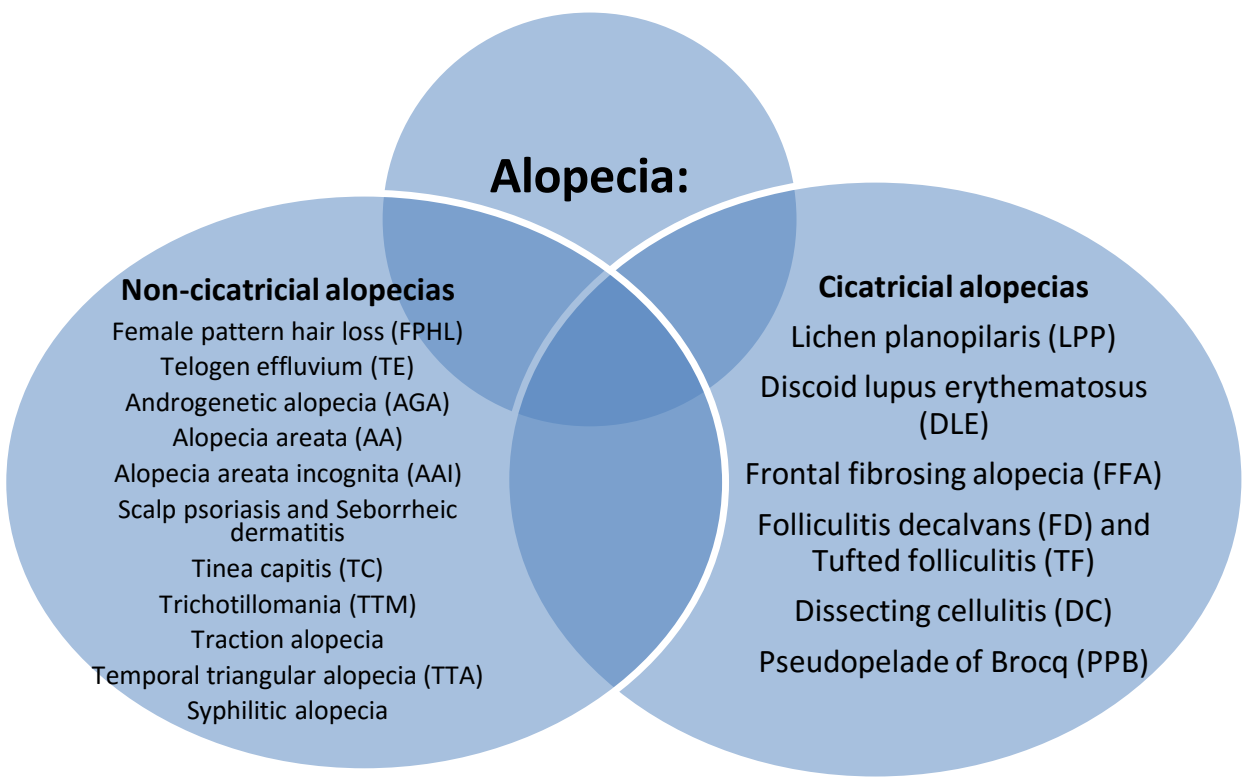

Diagram 2. Types of alopecia 


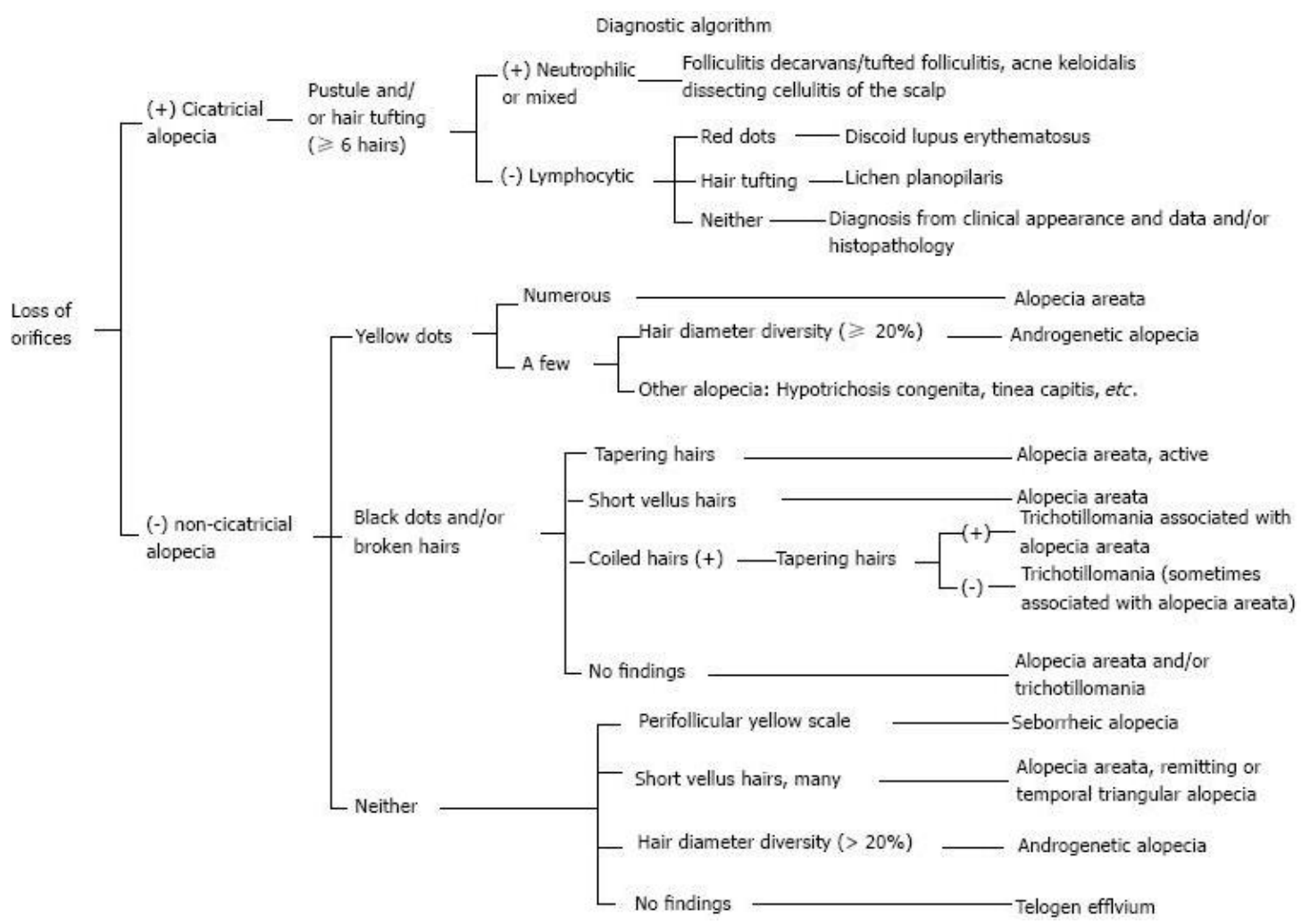

Chart 1. Diagnostic algorithm for trichoscopic findings of hair loss diseases ${ }^{[9]}$

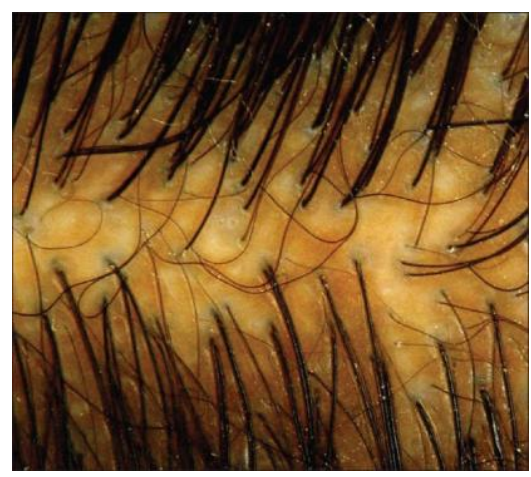

Figure 3. Anisotrichosis ${ }^{[8,19]}$

of catagen and telogen follicles, with premature termination of anagen follicles, while almost never causing obvious baldness. However, patients will panic and complain of the handful of hair shedding as it is severe during the earlier stages. Such patients are predominantly distressed by the ongoing hair loss and are afraid of total baldness.

TE is characterized by persistent excessive hair shedding, yet the loss of hair is replaced as rapidly as it sheds, so patients never become bald. It is due to the shedding of telogen hairs and it is the most frequent form of hair disorder seen in the clinical setting by dermatologists. It can be chronic and seen chiefly in women between the ages of 30-60 with full head of hair prior to the shedding incident. TE hair sampling will reveal telogen hairs in excess of $25 \%$ (normally $10 \%-15 \%$ ).

Effluvium can be based on two types: TE and anagen effluvium (AE) or defluvium. TE can be followed by any stressful events such as diet, pregnancy or illness, while AE follows certain medications and occurs much faster than TE, usually within one month or less after the event.

Trichoscopic findings: The presence of empty hair follicles and decreased hair density, one follicular hair unit dominance (Figure 4) and perifollicular discoloration (perpilar sign) with upright short hair regrowth ${ }^{[10]}$. TE is a diagnosis of exclusion.

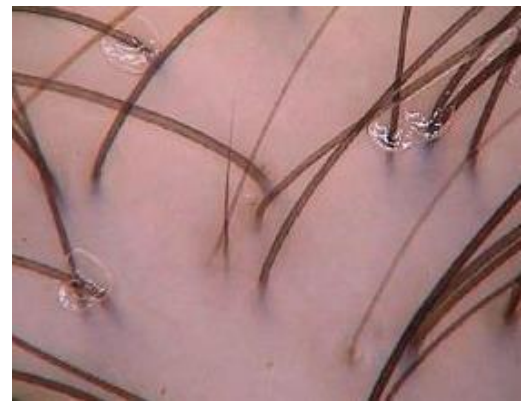

Figure 4. Upright hair in $\mathrm{TE}^{[13]}$ 


\section{Androgenetic alopecia}

The most common form of hair loss in both men and women, it is featured by a progressive loss of hair diameter, length, and pigmentation. Over time, it may become cosmetically unacceptable and psychologically frustrating to patients ${ }^{[14-16]}$. It is an inherited androgen-dependent state and is presumed to occur in genetically predisposed hair follicles, causing hair follicle miniaturization and thus causing a gradual substitution of large, pigmented terminal hairs by hardly seen depigmented vellus hairs in affected areas ${ }^{[16]}$.

In female androgenic alopecia (FAGA), focal areas of baldness (atrichia) are commonly seen. Male androgenetic alopecia is featured by its distinctive bi-temporal recession of hair and balding vertex, while FAGA, by its more disperse thinning of the crown area with an intact frontal hairline ${ }^{[8,16]}$.

Generally speaking, FAGA is clinically suspected in cases of frontal accentuation (Christmas tree pattern), central diffusion, or vertex/frontal and temporal (male pattern) with the sparing of the occiput (occipital area) (Figures 5-7 $^{[14,15]}$.

FAGA is the outcome of a progressive reduction of the anagen phase with miniaturization of the hair bulb, yielding TE and terminal-to-vellus hair conversion in the affected scalp area ${ }^{[14,16]}$.

Trichoscopic findings: Increased proportion of thin and vellus hairs, miniaturization, hair shaft thickness heterogeneity (anisotrichosis) (Figure 8), empty follicle $^{[16]}$, perifollicular discoloration (hyperpigmentation), the presence of a variable number of YD, and the decline in one follicular hair unit (Figures 8-11). Perifollicular discoloration of the skin is also known as "hyperpigmentation", "peripilar sign", or "peripilar halo" which denote the existence of perifollicular lymphocytic infiltration in early androgenic alopecia ${ }^{[2,14]}$. It has been suggested that $20 \%$ of women are diagnosed with FAGA $^{[14,17]}$. WD have been seen and suggested to be related to severe disease stage. They are represented by empty follicular opening (ostia) which is replaced by fibrosis in the advanced phase of the disease (Figure 12). According to Rakowska et al., the diagnosis of FAGA depend on some criteria ${ }^{[14,16,17]}$ :

Major criteria: 1) more than four empty follicles in four images (at 70-fold magnification) in the frontal area; 2) lower thickness in the frontal area compared to the occiput; 3) more than $10 \%$ of vellus (thin) hairs in the frontal area.

Minor criteria: 1) increased frontal to occipital ratio of single-hair pilosebaceous units; 2) vellus hairs; 3) perifollicular discoloration (peripilar signs).
Accomplishing two major criteria or one major and two minor criteria constitutes the diagnosis of FAGA with $98 \%$ specificity. According to Pedrosa et al., hair diameter diversity larger than $20 \%$ was confirmed to be the most consistent finding in AGA with perifollicular pigmentation $(\mathrm{PFP})^{[18]}$. Moreover, in FAGA, the number of YD and pilosebaceous units with only one hair and with perifollicular hyperpigmentation is significantly increased in androgenic alopecia.

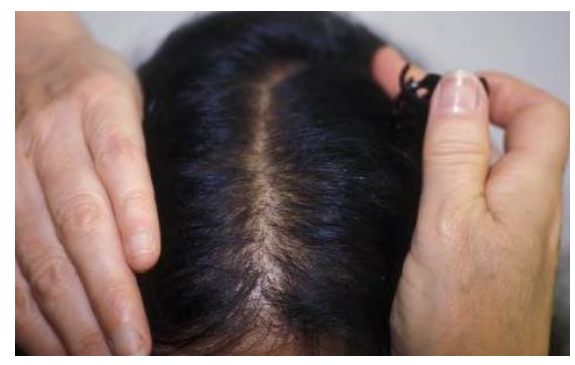

Figure 5. Christmas tree pattern, more parting. FAGA pattern of increased hair thinning, retention of the frontal hairline, and the presence of miniaturized hairs ${ }^{[2-4]}$.

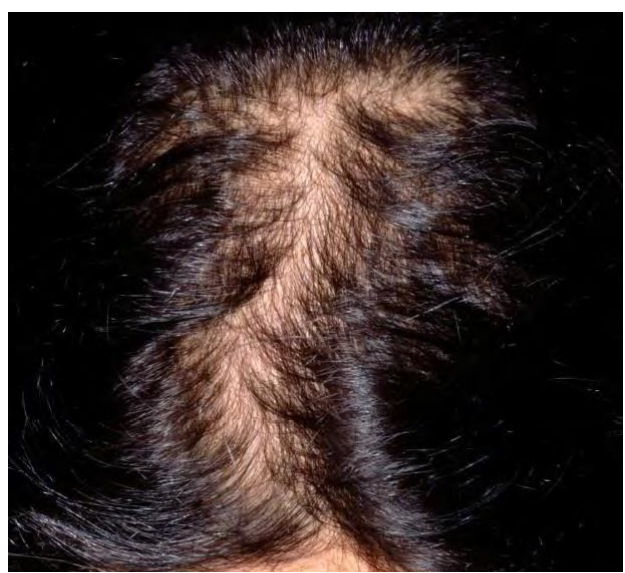

Figure 6. Frontal accentuations - Parting ${ }^{[5-6]}$

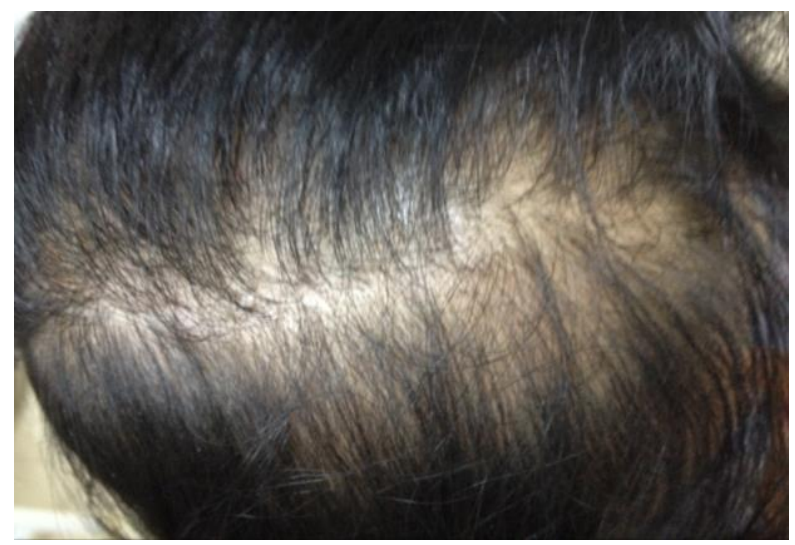

Figure 7. Distinctive parting with Christmas tree display 


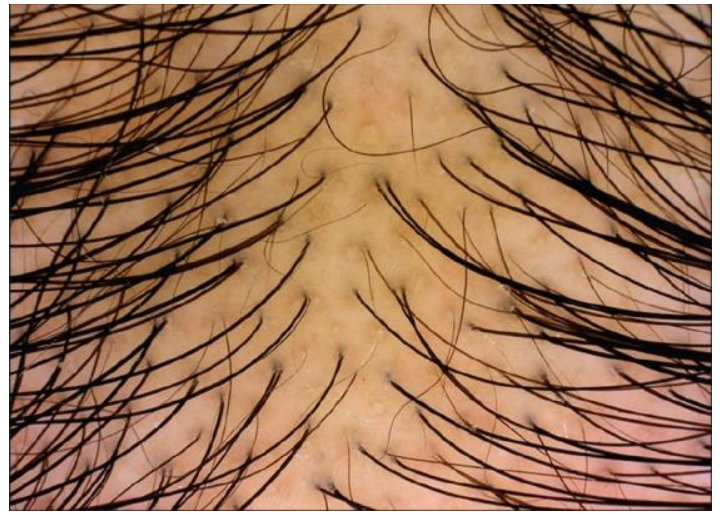

Figure 8. Anisotrichosis ${ }^{[5-7]}$

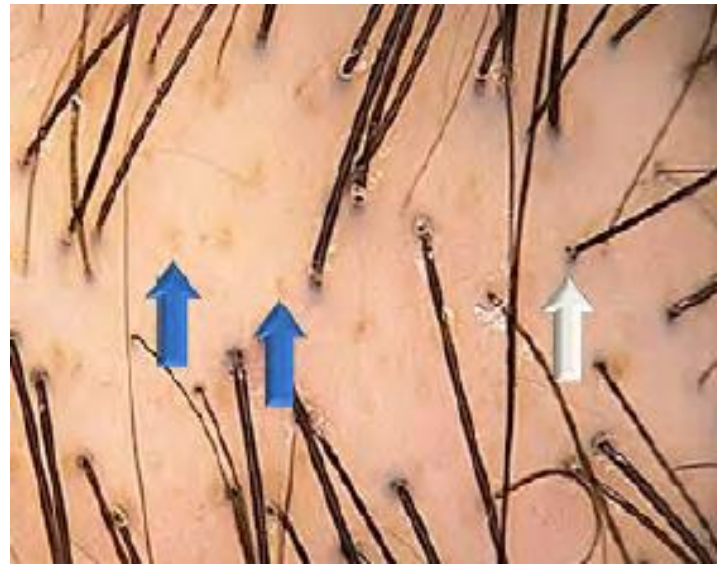

Figure 9. Yellow dots at blue arrow, and pigmentation at white arrow $^{[14]}$

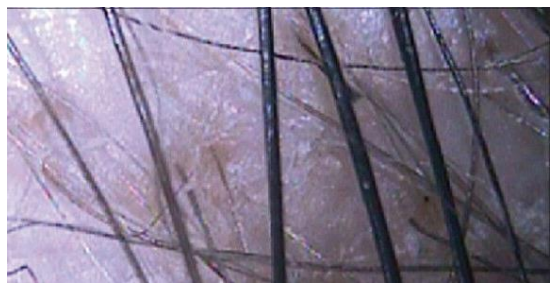

Figure 10. Yellow dots ${ }^{[5,6]}$

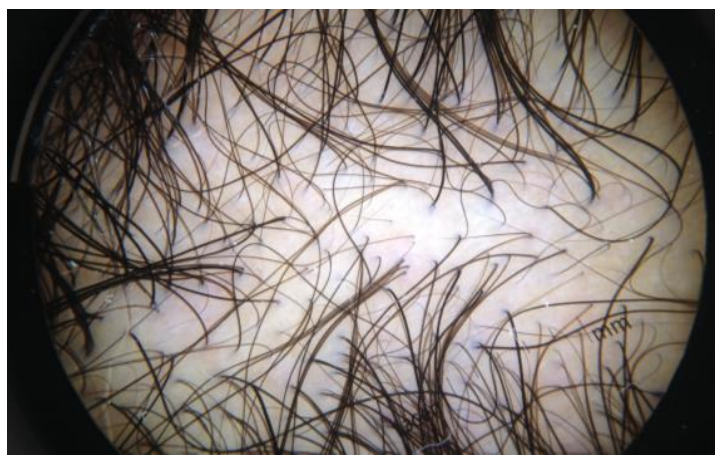

Figure 11. Anisotrichosis frontal

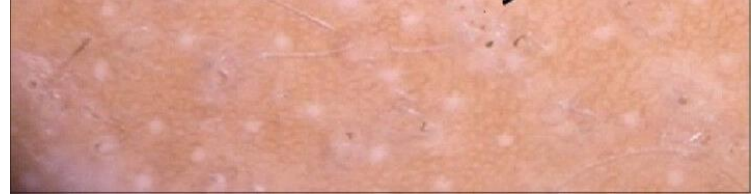

Figure 12. White dots ${ }^{[5,6]}$

\section{Alopecia areata}

AA is an autoimmune disease that disrupts anagen hair follicles ${ }^{[19]}$. It is manifested by an area on the head which is devoid of hair with smooth scalp. Hair starts to fall out suddenly, often in clumps. The amount of the hair loss varies, and it can be at a few round or oval localized areas or greater. It can be local to the scalp and can be generalized to all areas of the body. One form of AA is ophiasis which can mimic FFA, a cicatricial alopecia where hair follicles are lost ${ }^{[9]}$.

Trichoscopic findings: In active AA patients, the hallmark trichoscopic specific features are upright hair regrowth (Figures 13-18), tapered hairs (mark of active disease) (Figure 14), dystrophic hairs (broken hairs) (Figure 15), YD (Figure 16), uniform cadaverized hairs i.e. $\mathrm{BD}$, broken hairs (micro-exclamation mark hairs) (Figures 13-17), trichoptilosis, pig tails (Figure 18), and short vellus hairs. According to Rakowska et al., vellus hair was discovered to be a marker for long-lasting inactive disease process ${ }^{[14]}$. According to Pedrosa et al., uniform miniaturization of hair shafts is seen during remission ${ }^{[18]}$. Pig tails are hair regrowth coiled as a pigtail, as described by Rudnicka et al. (Figure 18) ${ }^{[6]}$. Previously, the exclamation mark was thought to be a sign for recovery and regrowth of hair. However, some studies had contradicted the concept of active disease findings. A Turkish study by Kibar et al. concluded that WD and BD were related to severe disease, while exclamation mark hairs were related to mild disease ${ }^{[20]}$.

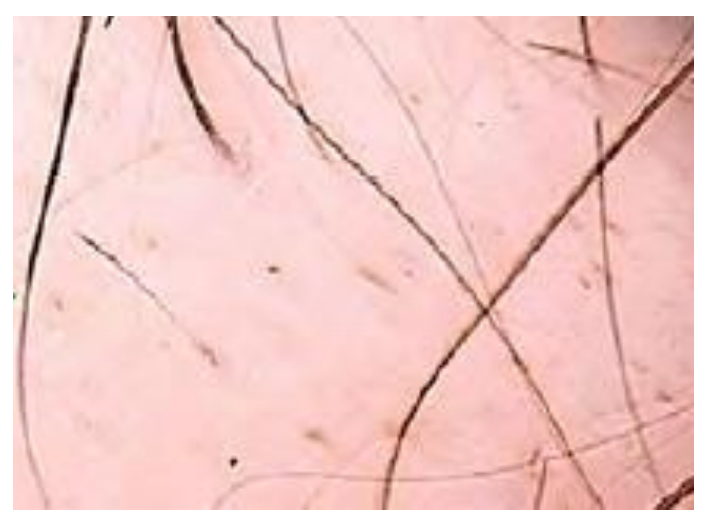

Figure 13. Black dots, micro exclamation hair mark ${ }^{[14-16]}$ 


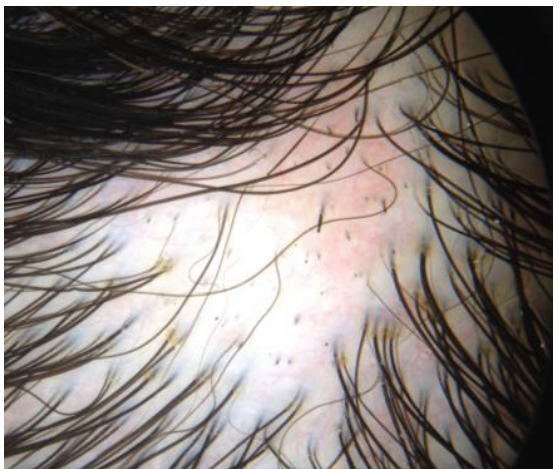

Figure 14. Black dots, cut hair, micro-exclamation hair mark, and tapered hair

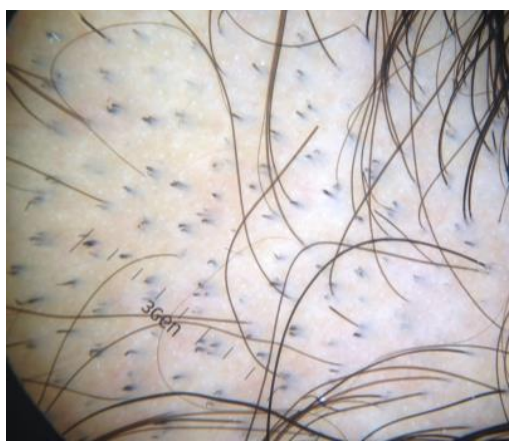

Figure 15. Multiple white dots and broken hair (dystrophic)

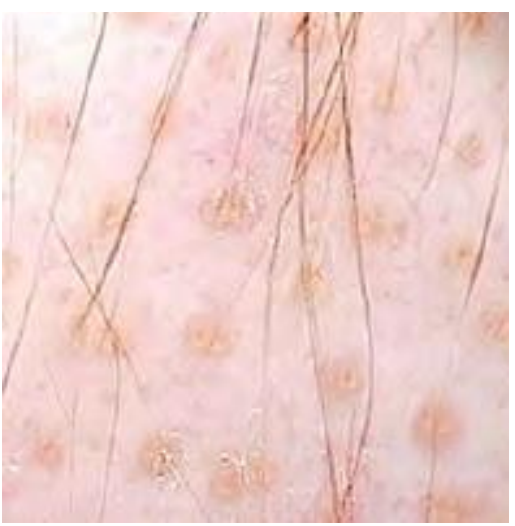

Figure 16. Yellow dots ${ }^{[14-16]}$

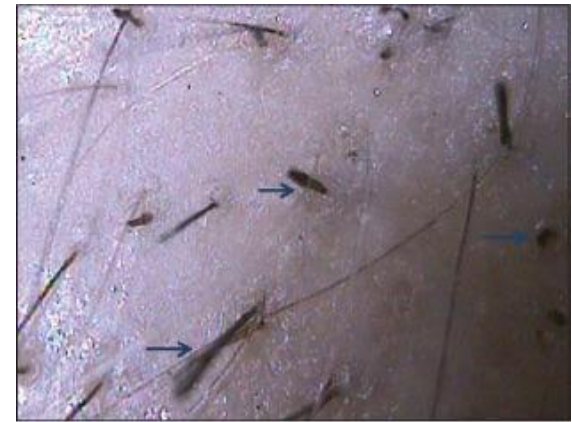

Figure 17. Exclamation mark hair ${ }^{[17]}$

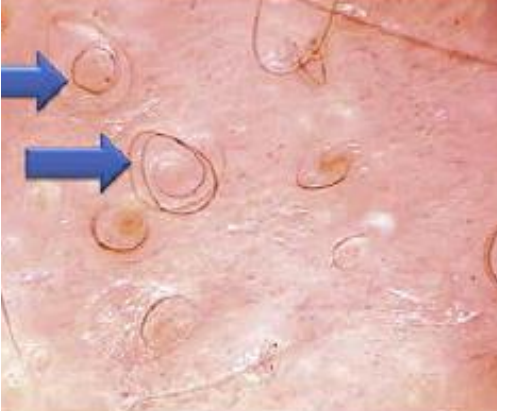

Figure 18. Pig tails ${ }^{[14]}$

\section{Alopecia Areata Incognita}

AAI is considered by some as a variety of alopecia areata (diffuse-type AA), characterized by acute diffuse shedding of telogen hairs, and trichodynia. It stimulates AGA and TE with the occurrence of disperse and severe hair thinning in a short time ${ }^{[9]}$. Molina et al. stated that AAI affects mostly women below age forty; however, there has been some disagreement ${ }^{[21]}$.

Trichoscopic findings: According to Tosti and Duque-Estrada, there are numerous diffuse YD of different sizes and of uniform colors within both empty and hair-bearing follicular orifices, with a large number of regrowing of tapered terminal hairs in the entire scalp (Figure 19) $^{[7]}$.

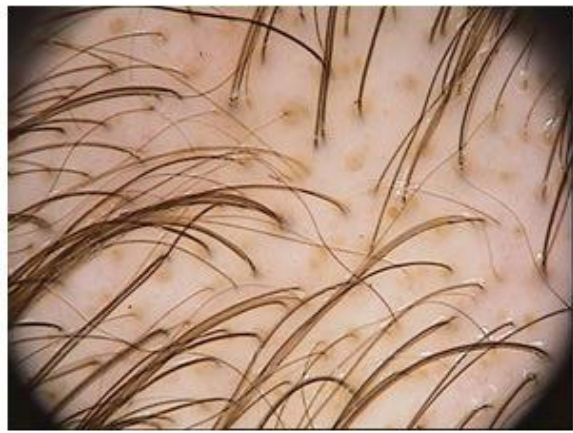

Figure 19. YD in whole scalp: Hairy and non-hairy areas and up-growth of hair ${ }^{[2-3]}$.

\section{Scalp psoriasis and seborrheic derma- titis}

Psoriasis and seborrheic dermatitis are equally chronic erythemato-squamous dermatoses that can involve the scalp. It may be hard to clinically distinguish between both when it affects only the scalp, and thus it poses a diagnostic challenge ${ }^{[22,23]}$. However, the involveement of frontal hair lines is distinctive for scalp psoriais. 
Psoriasis is characterized by silvery-white scaling while seborrheic dermatitis is featured by red, flaking, and greasy areas.

Trichoscopic findings: Atypical red vessels (ARV), RDG (Figure 20), signet ring vessels (SRV) (Figure 21), structureless red areas (SRA), glomerular vessels (GV), twisted red loops (TRL), PFP, and hidden hairs $(\mathrm{HH})$ were seen mostly in psoriasis while TRL and comma vessels (CV) (Figure 22) were specific for seborrheic dermatitis $^{[22,23]}$. Additionally in seborrheic dermatitis, arborizing red lines (ARL), HH (Figure 23), perifollicular white scale, TRL, ARV, SRA, GV, yellow dots (YD), PP, SRV, CV, honeycomb pigment pattern, and brown dots can be seen. As a standard, RDG are considered as the characteristic for psoriasis while ARL and CV for seborrheic dermatitis ${ }^{[22]}$.

RDG signify tortuous and dilated blood vessels within the elongated dermal papillae (Figure 20). While arborizing blood vessels and ARV depict marked dilated capillaries in slightly hypertrophic rete ridges, in seborrheic dermatitis, the blood vessels proliferate horizontally in the subpapillary plexus associated with perivascular inflammation $^{[22]}$.

$\mathrm{SRV}$ is formed due to vascular alteration in psoriasis and seborrheic dermatitis, and it depicts a slightly tortuous glomerular vessel. It is characterized by an elongated and dilated annular ring shaped vessel ${ }^{[22,23]}$. This vascular sign, however, was not observed in other alopecias and thus it is considered as a specific sign for these two dermatoses $^{[22]}$.

$\mathrm{HH}$ is due to perifollicular and epidermal proliferation and infiltration, together with an altered hair shaft with macropits (lips of follicular ostia infiltration), which would cause the proximal hair shaft to seem hidden under this thickened epidermis (Figure 23). As a result of these epidermal and perifollicular inflammations, the pilosebaceous unit with proximal hair shafts may be fairly hidden under the white-grey epidermal proliferations $^{[22]}$.

According to a study by Kim et al., the main trichoscopic figures typically seen in psoriasis were RDG, TRL, and GV; while ARV, ARL, and SRA were seen in seborrheic dermatitis with absence of $\mathrm{RDG}^{[23]}$. Kibar et al. observed that RDG, ARV, SRA, HH, and SRV were chiefly seen in psoriasis while TRL and CV were seen in seborrheic dermatitis ${ }^{[20]}$. Both cases showed scales.

In short, when comparing psoriasis and seborrheic dermatitis trichoscopy findings; ARV, RDG, SRV, SRA, and $\mathrm{HH}$ are significantly more common in psoriasis while TRL and CV are significantly more common in seborrheic dermatitis.

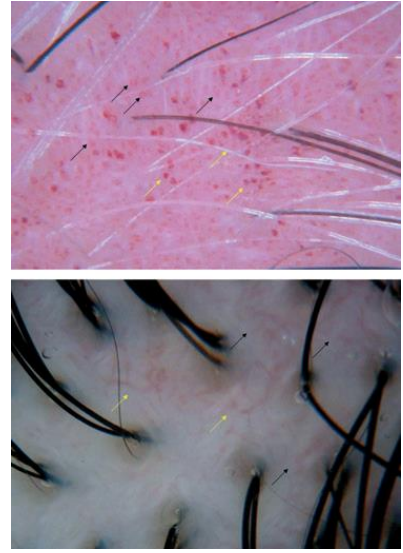

Figure 20. Red dots and globules (top) and arborsing vessels (bottom) ${ }^{[23-24]}$

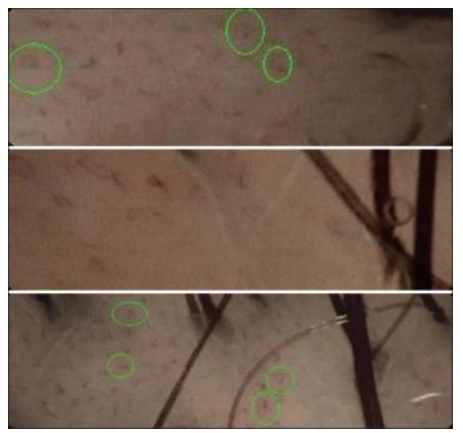

Figure 21. Singlet ring vessel ${ }^{[23]}$

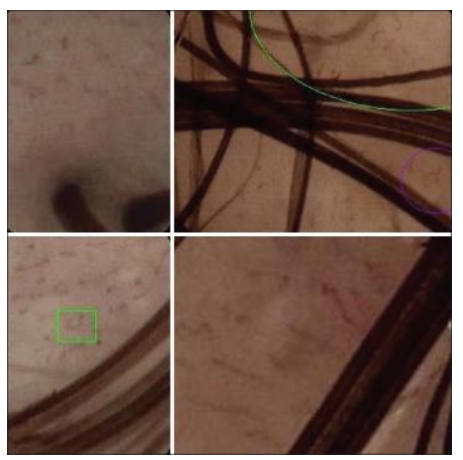

Figure 22. Comma vessels ${ }^{[24]}$

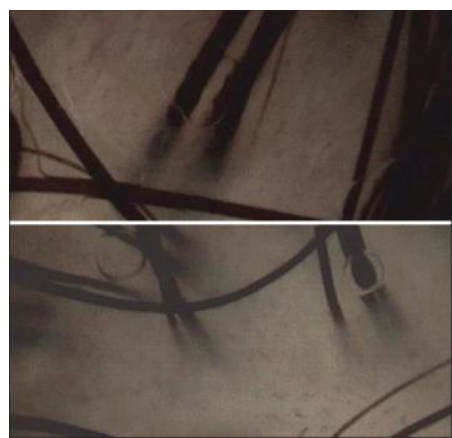

Figure 23. Hidden hairs with psoriasis (top) and with seborrheic dermatitis (bottom) ${ }^{[23]}$ 


\section{Tinea capitis}

A frequent condition caused by superficial fungal infection of the scalp, it is mostly encountered in children. It is primarily inflicted by dermatophytes, explicitly Trichophyton and Microsporum that intrude hair shafts. The clinical picture is typically single or multiple patches of hair loss, occasionally with a "black dot" outline which might be accompanied by inflammation, scaling, pustules, oozing pus, and itching (kerion).

Trichoscopic findings: Comma-shaped hairs (Figure 24), corkscrew hairs, BD, short broken hairs, and zigzag-shaped hairs are the diagnostic trichoscopic features of TC (Figures 25 and 26) ${ }^{[24]}$. According to Rudnicka et al., the main trichoscopic features are comma hairs and the slightly curved and fractured hair shafts that are associated with ectothrix and endothrix type fungal invasions $^{[3]}$. Comma hairs are probably shaped as a result of subsequent cracking and bending of hair shafts filled with hyphae. Zigzag-shaped hairs or corkscrew (twisting-coiled) hair is a variant of the comma hair, manifesting typically among patients of African ancestry. The term "tapering hair" is favored over "micro-exclamation mark hair" because the affected hair is not a typical exclamatory mark in shape. It is due to the tapering of hair shafts toward the follicles, which is captured by trichoscopy rather than the naked eye. Tapering hair is considered as a marker of disease activity and is known to reflect exacerbation of disease. BD are remnants of broken hairs or dystrophic hairs, such as the exclamation mark hairs, occurring when the hair shaft is fractured before emerging from the scalp. BD provide a sensitive marker for disease activity and severity of AA. According to a study by Rudnicka et al., white hairs were detected in $45 \%$ of AA cases; it was believed to be a diagnostic trichoscopic finding denoting spontaneous remission of $\mathrm{AA}^{[3]}$.

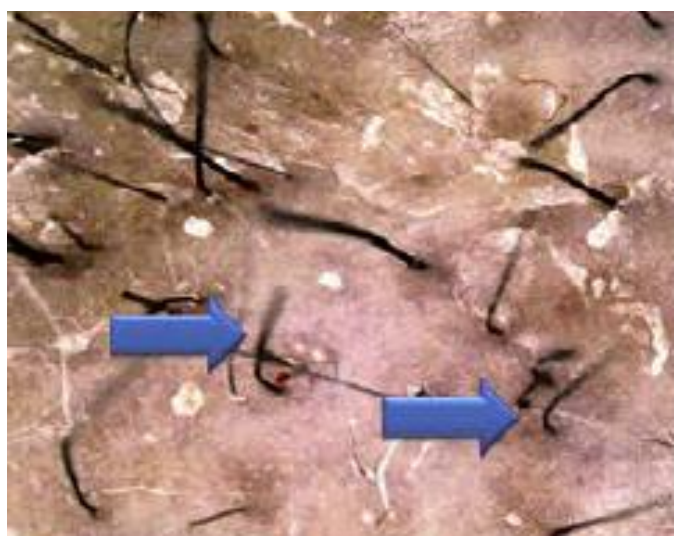

Figure 24. Comma hairs ${ }^{[2,14]}$

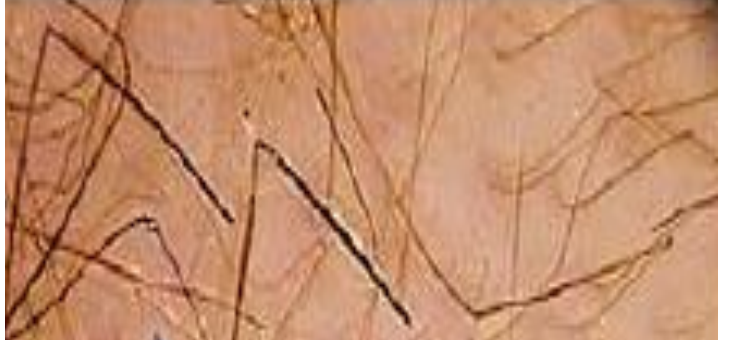

Figure 25. Zigzag hairs ${ }^{[2,14]}$

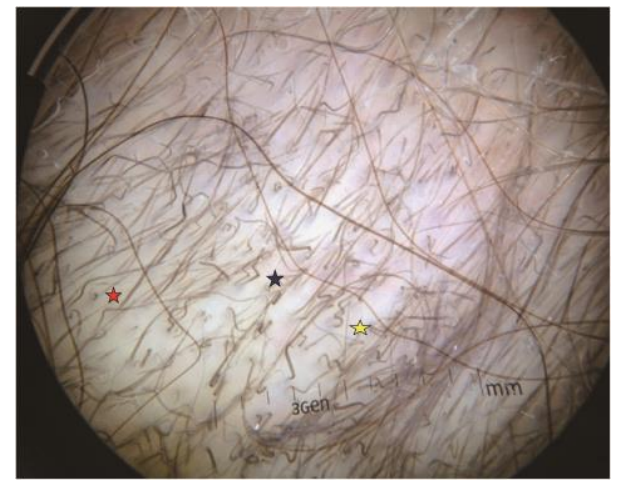

Figure 26. Comma (red asterisk), corkscrew (yellow asterisk), and zigzag hairs (blue asterisk)

\section{Trichotillomania/trichotillosis}

It is a self-inflicted injury and is characterized by punctuate alopecia of hair-bearing areas. Traction alopecia also falls under this category, which arises due to hairstyling procedures. It factually means a dismal urge and craving to repeatedly pull out hair, with a sense of pleasure, gratification or relief after the hair is plucked. The pulling behavior serves as a coping mechanism for anxiety, stress, and other difficult emotions. The favored location is the easily accessible fronto-parietal area of the scalp, followed by the eyelashes, eyebrows, pubic hair, body hair, and facial hair. TTM is derived from Greek - thrix meaning hair, tillo meaning to pull out and mania meaning madness - coined by Hallopeau in $1889^{[25]}$. The incidence is unknown but estimated to affect about $4 \%$ of the general population and is commonly encountered in children and adolescents. The usual pattern is called the tonsure pattern which is also referred to as the "Friar Tuck" sign. It is considered to be amongst the psycho-cutaneous diseases as it is associated with psychiatric comorbidity, social and functional hurt ${ }^{[26-30]}$. It can be easily diagnosed by an experienced dermatologist as, clinically, there is decreased hair density with broken hairs at different levels ${ }^{[30]}$.

Trichoscopic findings: Short hair with trichoptilosis "split ends" and irregular coiled hairs, upright hair re- 
growth and BD; additional findings include flame hair, V-sign, follicular hemorrhages, decreased hair density, broken hairs at different levels, and absence of exclamation signs $^{[29]}$. Recently, tulip hair and hair powder were observed as well in some cases ${ }^{[25,28,30]}$. Coiled hair is incurred due to hair shaft fracture caused by the persistent urge of pulling and coiling of residual proximal part which is attached to the scalp ${ }^{[28]}$. According to Mathew, there are regularly distributed YD (hyperkeratotic plugs in the hair follicles), cadaverized hairs i.e. BD, micro-exclamation mark hairs (visible at $1 \mathrm{~mm}$ or less in length), and dystrophic hair regrowth ${ }^{[27]}$.

Recent trichoscopic findings revealed decreased hair density, vellus hairs, broken hairs, hair with trichoptilosis (split end), coiled hairs, flame hairs, tulip hairs, V-sign, $\mathrm{BD}$, and broom fibers. Yorulmaz et al. not only demonstrated typical trichoscopic features of TTM such as broken hairs, vellus hairs, BD, coiled hairs, and trichoptilosis, but Yorulmaz's study also displayed newly defined findings like tulip hairs, flame hairs, and V-sign (Figures 27-29) ${ }^{[26]}$. The V-sign is created when two or more hairs originating from one follicular unit are broken at equal levels. It is believed that recently defined pathognomonic finding for TTM is flame hairs. Generally noticed in active TTM, flame hairs are observed after severe mechanical trauma. Rakowska et al. and Rudnicka et al. ${ }^{[30]}$ noted that BD are uniform in size and shape in $\mathrm{AA}$, whereas in TTM and tinea capitis, they were irregular in diameter and shape ${ }^{[14,31]}$. Follicular micro-hemorrhage is a diagnostic sign of TTM. It appears as a red dot corresponding to follicular ostia that is swollen with blood clot due to traumatic forceful hair plucking. It was recently proposed that flame hairs, V-sign, tulip hairs, and hair powder were emphasized explicitly for diagnosing $\mathrm{TTM}^{[26,30]}$. Flame hairs are semi-transparent, wavy, and cone-shaped hair remains that occur due to strict mechanical hair pulling and tear-ups. V-sign happens when two or more hairs come out from one follicular unit, which are pulled concomitantly and fractured at the same length above the scalp surface. Tulip hairs are short hairs with darker, tulip-flower-shaped ends. These develop when a hair shaft fractures obliquely. When a hair shaft is almost totally damaged by unconscious handling, only dotted hair residue is visible. This feature is called hair powder. Finally, histopathology plays a corroborative role in definitive diagnosis. It is hard to distinguish between TTM and AA; a histological reading is needed to specify the right diagnosis since empty hair follicle, incomplete disrupted folicular anatomy, trichomalacia and pigment casts without significant inflammation are only seen in $\mathrm{TTM}^{[27]}$.

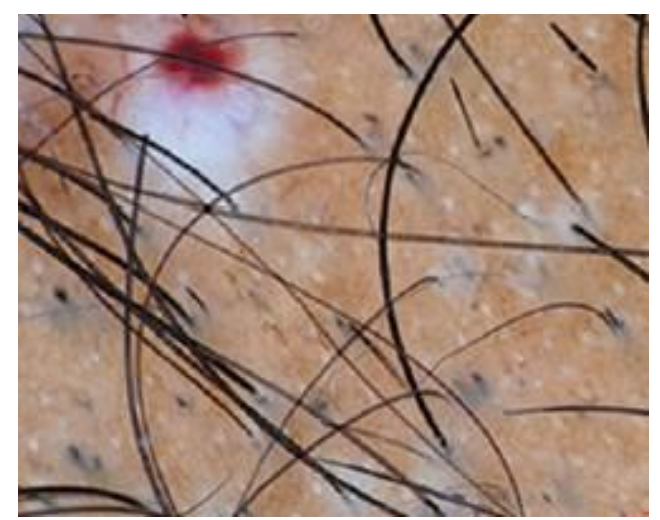

Figure 27. Follicular hemorrhage, black dots, V shape, and tulip hair ${ }^{[5,26]}$

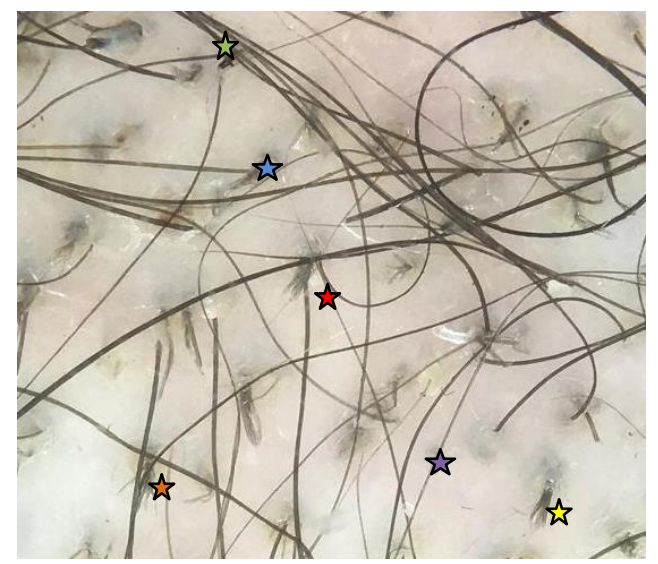

Figure 28. Split ends (orange asterisk), broom (blue asterisk), powder (violet asterisk), flame (green asterisk), and V-sign hairs (yellow asterisk)

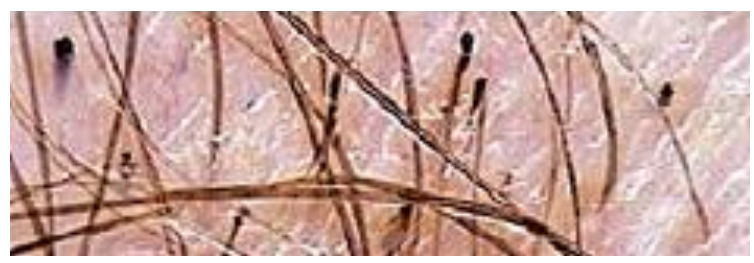

Figure 29. Tulip hairs ${ }^{[27-28]}$

\section{Traction alopecia}

Traction alopecia is caused by hair styling and shares some features of TTM trichoscopic readings along with some hair casts, WD lacking follicular opening, hair thinning, and decreased hair density ${ }^{[30]}$.

\section{Temporal triangular alopecia}

TTA is also referred as congenital triangular alopecia, Brauer nevus or "alopecia triangulaire congenitale de la 
temp", and mostly seen between 2-9 year-olds and even in adulthood in the fronto-temporal section. It is not congenital, though. It is featured by rounded, triangular or oval non-scarring alopecia and the main confusion is AA. It is a rare, stable, and benign dermatosis of unknown cause ${ }^{[31,32]}$.

Trichoscopic findings: Normal follicular openings with vellus hairs surrounded by the terminal hairs can be appreciated (Figure 30), with absence of YD and/or $\mathrm{BD}$, brittle hair, and exclamation mark hairs.

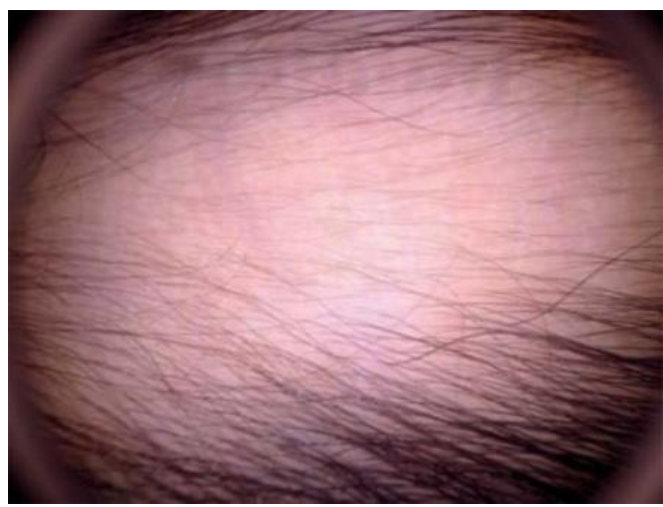

Figure 30. Normal follicle orifices and vellus hairs

\section{Syphilitic alopecia}

Syphilitic alopecia is not common in patients with secondary syphilis. However, it is known as moth-eaten alopecia (various small, scattered, and non-scarring hairless patches with incomplete hair loss, which is irregular in size and without defined borders).

Trichoscopy findings: Previous trichoscopic features of syphilitic alopecia have not been looked into. According to Ye et al., BD, focal atrichia, hypopigmentation of hair shaft, empty ostia of hair follicle and YD (Figure 31) are symptoms of syphilitic alopecia ${ }^{[33]}$.

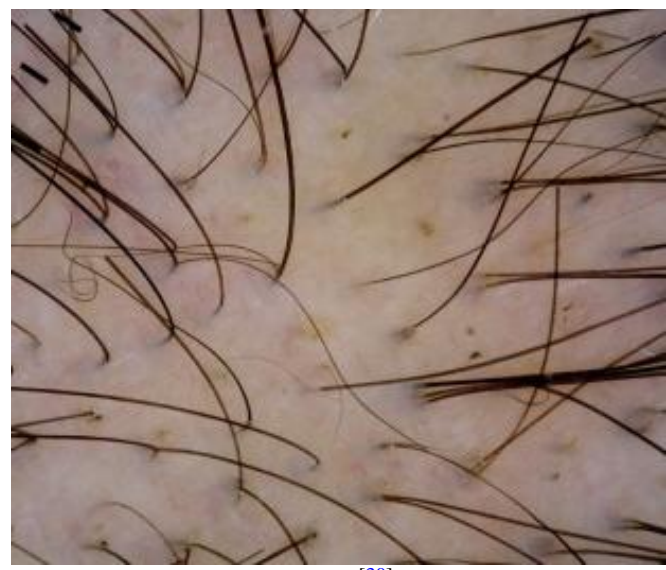

Figure 31. Black and yellow dots ${ }^{[30]}$

\section{Cicatricial alopecias}

Recently, it has been revealed that scarring are incurred due to permanent abuse of the stem-cell-rich bulge area of the hair (Figure 32) which is obligatory for cyclic regeneration of the lower follicle ${ }^{[7]}$. Thus, in any trichoscopy, we can anticipate no hair follicle orifice and a fibrous white band.

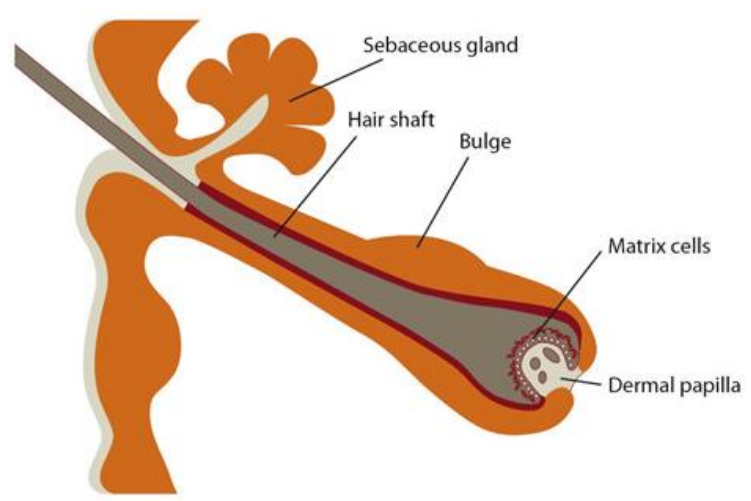

Figure 32. Hair bulge area ${ }^{[43]}$

\section{Lichen planopilaris}

Clinically, it appears to manifest as purplish plaques affecting the central aspect of the mid scalp, and finally with atrophy and irreversible alopecia of the scalp. The pull test is positive for anagen at the site of active disease. Atrophy and permanent alopecia of the scalp may result in time ${ }^{[34,35]}$. Lichen planus (LP) usually affects the interfollicular skin; however, LPP affects hair follicles with the sparing of interfollicular areas ${ }^{[10]}$.

Trichoscopic findings: Tubular perifollicular scaling due to perifollicular inflammation (peripilar casts seen at the periphery of the patch) and perifollicular erythema (arborizing vessels around the follicular ostia) due to perifollicular inflammation, with elongated blood vessels observed in lichen planopilaris ${ }^{[34]}$. Hair tufting can be seen in some cases ${ }^{[18]}$. Peripilar casts can be seen as "blue-grey dots" which denote perifollicular pigment incontinence (Figures 33 and 34). Chronic inflammation leads to fibrosis which is seen as WD (Figure 35) ${ }^{[36]}$.

\section{Discoid lupus erythematosus}

Clinically appearing as erythematous scaly plaques in the early stages, lesions would get thickened with adherent scales and follicular plugging ${ }^{[33]}$. In a later stage, the lesions would become depressed, depigmented, and telangiectasia. In DLE, there is complete loss of follicular 


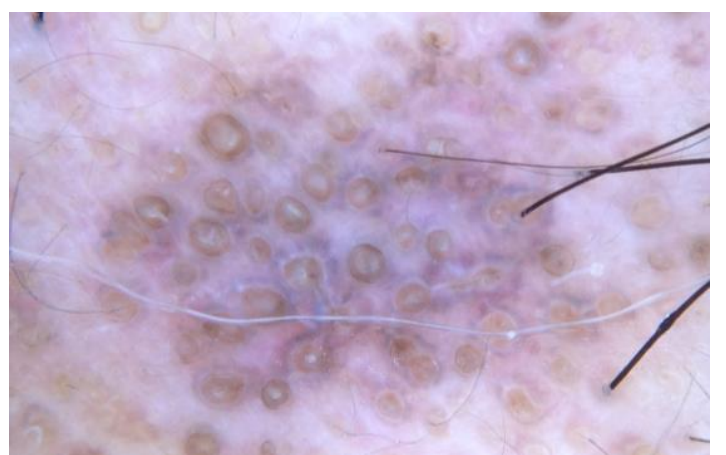

Figure 33. Perifollicular blue grey dots in circular manner sparing interfollicular area (DLE) (targetoid)

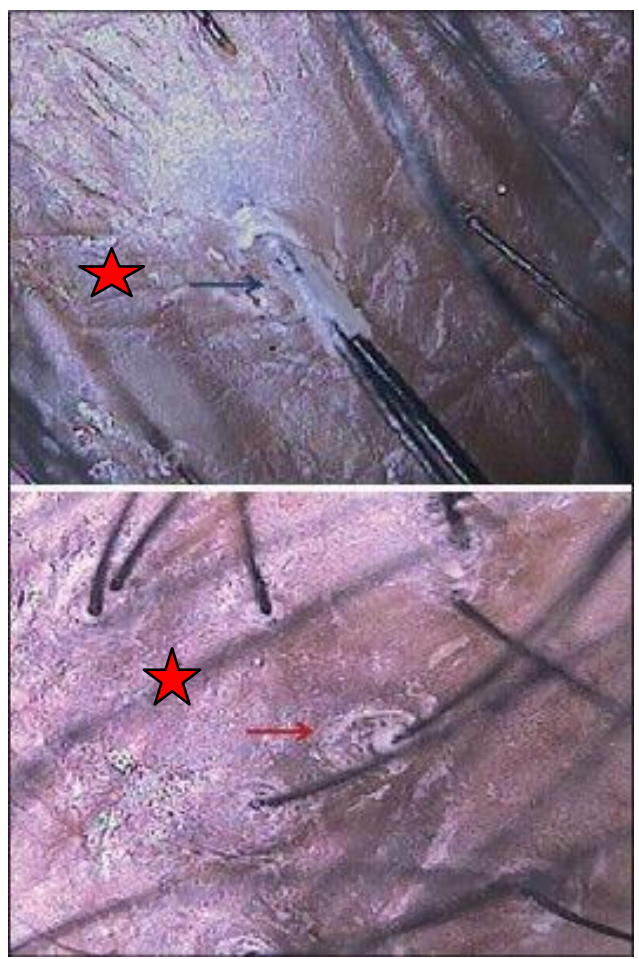

Figure 34. Intense perifollicular and tubular scales/casts ${ }^{[31,33,34]}$

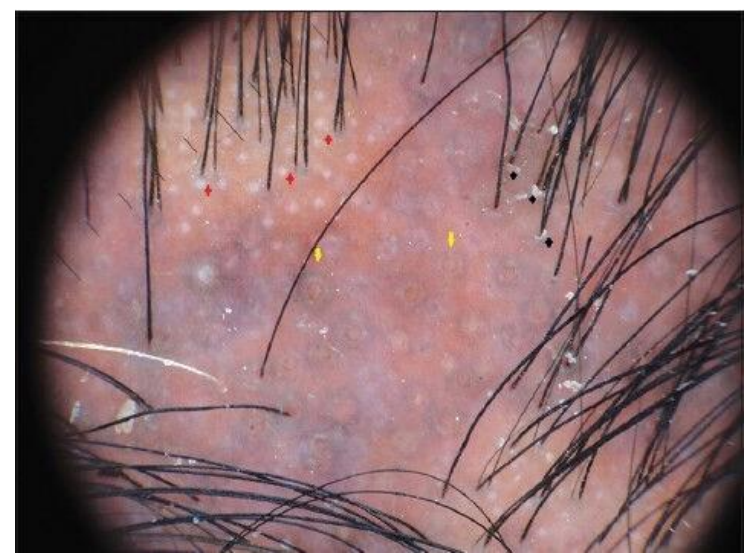

Figure 35. White dots of $\mathrm{LPP}^{[1-3]}$ openings. Arborizing telangiectasia can be visualized over the patch. Prominent hyperkeratotic follicular plugging is seen at the periphery of the plaque. DLE affects interfollicular area, contrasting with LPP which is concentrated around the follicles ${ }^{[10]}$. DLE may show hair regrowth if promptly treated and thus early treatment is important $^{[36,37]}$.

Trichoscopic findings: Scattered dark-brown discoloration of the skin, large YD and thick arborizing vessels in cutaneous (discoid) lupus erythematosus (Figures 36 and 37) ${ }^{[36,37]}$. Scalp atrophy is identified by a diffuse white color of the scalp ${ }^{[7]}$. Arborizing and tortuous vessels are visualized inside DLE plaques ${ }^{[8]}$. Red to pinkish-red, round, and polycyclic dots of uniform size are often scattered around follicular openings, which may be a peculiar finding as well. According to Pedrosa et al., follicular red dots seem to be a specific finding of scalp DLE, which denotes an active disease ${ }^{[18]}$.

Follicular red dots with reduced follicular ostia, arborizing vessels, white patches, honeycomb pigmented network (Figure 37), blue-grey dots, and variable scaling are found in DLE. Keratotic plugs represent the clinical signs of carpet tack (Figure 36). Numerous yellow follicular keratotic pluggings (markers of early active DLE) are seen, which are a typical feature of DLE that can be easily identified ${ }^{[36,37]}$.

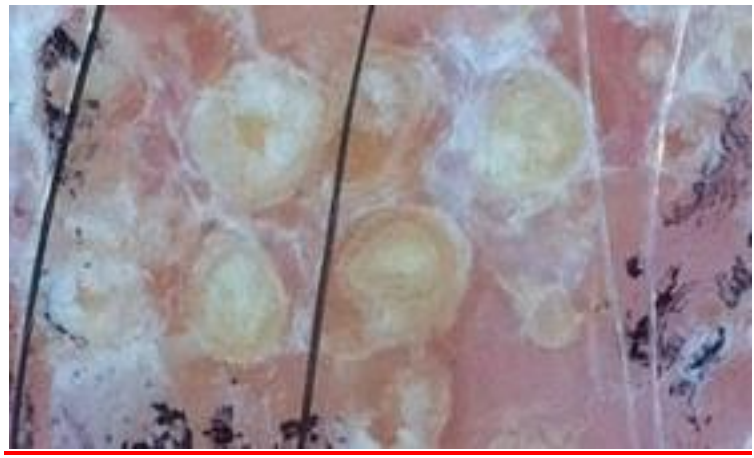

Figure 36. Numerous large yellow Follicular keratotic plug$\operatorname{ging}^{[34]}$

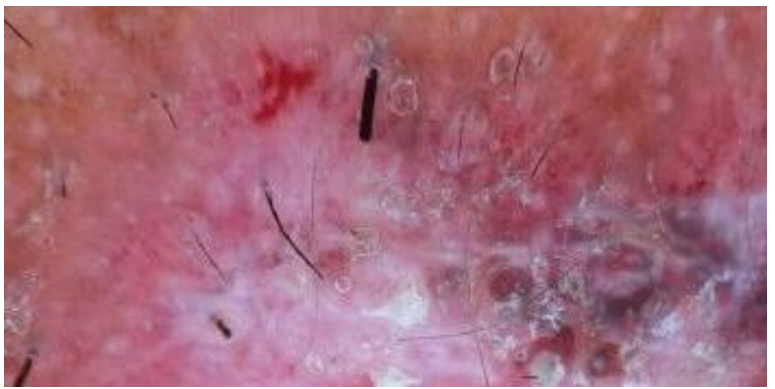

Figure 37. Thick arborizing blood vessels and red follicular dots interspersed with scar areas ${ }^{[34]}$ 


\section{Frontal fibrosing alopecia}

FFA is distinguished by the recession of the fronto-temporal hairline (FTHL) with alopecic scarring change (such as hairband retraction, loss of eyebrows, and orphaned hairs). It is usually associated with alopecia in other non-scalp locations. FFA disease appears only in postmenopausal women, with no hormonal status association. However, other FFA clinical manifestations such as axillar or eyebrow alopecia, LPP or pruritus appear in variable frequency, except for the mentioned recession of the hairline present in all patients ${ }^{[38]}$. FFA is considered by some as a probable clinical variant of LPP, which exhibits similar histopathological readings. Usually FFA has been connected with the postmenopausal state in women even though not all patients with this diagnosis are postmenopausal.

Trichoscopic findings: The absence of follicular opening, with presence of follicular hyperkeratosis, follicular plugs, and erythema. According to Toledo et al., the presence of perifollicular erythema will be a direct marker of FFA activity (Figure 38) ${ }^{[38]}$. Minor perifollicular scaling is present in $\mathrm{FFA}^{[34]}$.

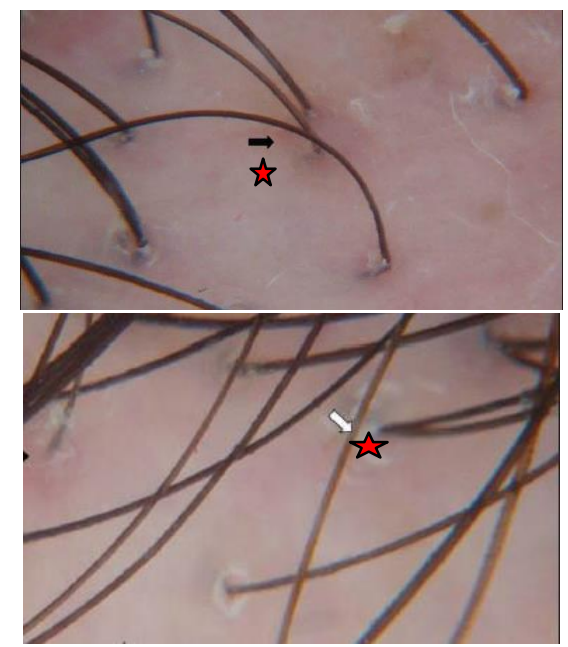

Figure 38. Absence of follicular openings, dominance of follicular units with only 1 hair, mild perifollicular scaling and perifollicular erythema, and hyperkeratosis, follicular plugs and erythema $^{[35]}$

\section{Folliculitis decalvans and tufted fol- liculitis}

FD (baldness with scarring) is a category of alopecia that is connected with scarring involving the vertex and the occipital. In Latin, it means "to remove hair". It is characterized by redness, swelling, and pustules oozing pus around the hair follicle which leads to inflammation of the hair follicle (folliculitis) with damage to the hair follicle, and thus enduring hair loss with scarring and loss of follicular openings. It is also called TF, characterized by "polytrichia" which is multiple hairs emerging from a single dilated follicular orifice ${ }^{[39]}$.

Trichoscopic findings: The hallmark is the emergence of multiple hairs from a single dilated follicular opening (5-20 or more) polytrichias with a band of yellow scales at the base of the hair, and perifollicular hyperplasia that is arranged in a starburst pattern (starburst sign) in $\mathrm{FD}^{[39,40]}$. According to Fabris et al., there are follicular tufts (Figure 39), perifollicular erythema (Figure 40), yellowish tubular scaling, crusts, and pustules ${ }^{[39]}$. Follicular scaling and pustules represent follicular inflammation and an active disease ${ }^{[10]}$. Multiple follicular pustules can be seen at the active border. Twisted capillary loops may be visualized in the interfollicular region. When the disease is inactive, the long- standing disease yields scarred areas which are seen as pinkish-white patches with absence of follicular openings ${ }^{[10]}$.

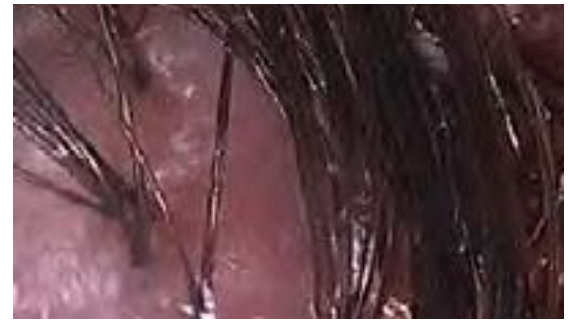

Figure 39. Tufted hair ${ }^{[13]}$

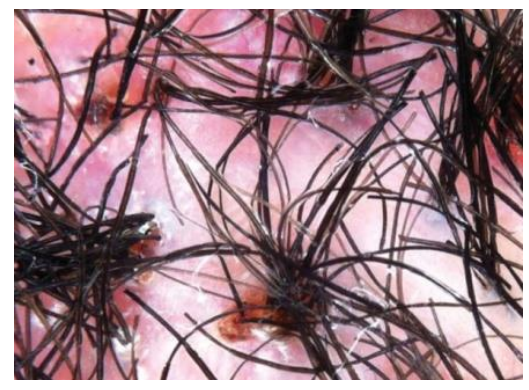

Figure 40. Polytrichia and redness ${ }^{[37]}$

\section{Dissecting cellulitis (dissecting follicu- litis)}

It is a rare progressive chronic condition that affects the scalp vertex and posterior neck, commonly seen in young males of African ancestry (skin type 5 and 6) between ages $20-40$, and is often called doll hair. It starts clinically as simple folliculitis or perifolliculitis, which then 
rapidly erupts as multiple painful nodules with purulent discharge that coalesce to form interconnecting abscesses and sinuses. Pus can be expressed by exerting pressure. The scalp is boggy and causes scarred hair loss, eventually prompting either hypertrophic or atrophic scarring of the scalp.

Trichoscopic findings: Yellow structureless areas, with "3D" YD (soap bubble) structure imposed over dystrophic hair shaft (Figure 41), which can sometimes be seen with some BD and pin-point vessels with white halo, and with no follicular opening and fibrosis ${ }^{[41]}$. Those bubbles are due to dense neutrophilic dermal infiltrate ${ }^{[41]}$

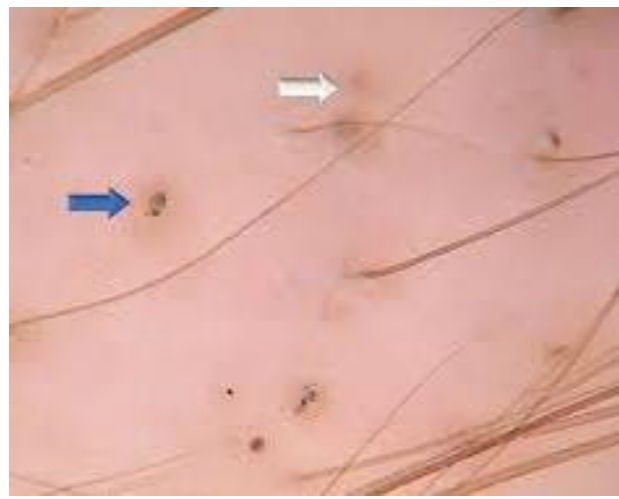

Figure 41. 3D yellow dots with or without black dots in their center (soap bubble) ${ }^{[30]}$

\section{Pseudopelade of Brocq}

PPB is a remarkable form of continuing aleopecia of the central scalp for at least two years without affecting the eyebrows, mostly affecting middle aged and older women, and is slowly progressive without noted inflammation. Its causes are unidentified, are diagnosed by excluding LPP and DLE, and are described as 'foot prints in the snow'. It can be distinguished from AA by irregular asymmetrical smooth patches without follicular orifices. PPB is not an inflammatory form of alopecia, and hair loss is due to atrophy of hair follicles by lymphocyte invasion rather than scarring. However, some authors argued that it is the end-stage of other inflammatory cicatricial alopecias such as LPP, but this is yet to be confirmed $^{[42]}$.

Trichoscopic findings: According to Olszewska et al., trichoscopic features of classic Pseudopelade of Brocq are nonspecific ${ }^{[40]}$. It can manifest as smooth porcelain white skin to slight red tint with no follicular openings (Figure 42). Some solitary dystrophic hairs can also be seen at the periphery of the lesion with no indicative features of other cicatricial alopecia. In short, when there are no tubular perifollicular scales of LPP, no starburst hyperplasia of FD, and no arborizing vessels of DLE, the diagnosis is $\mathrm{PPB}^{[42]}$.
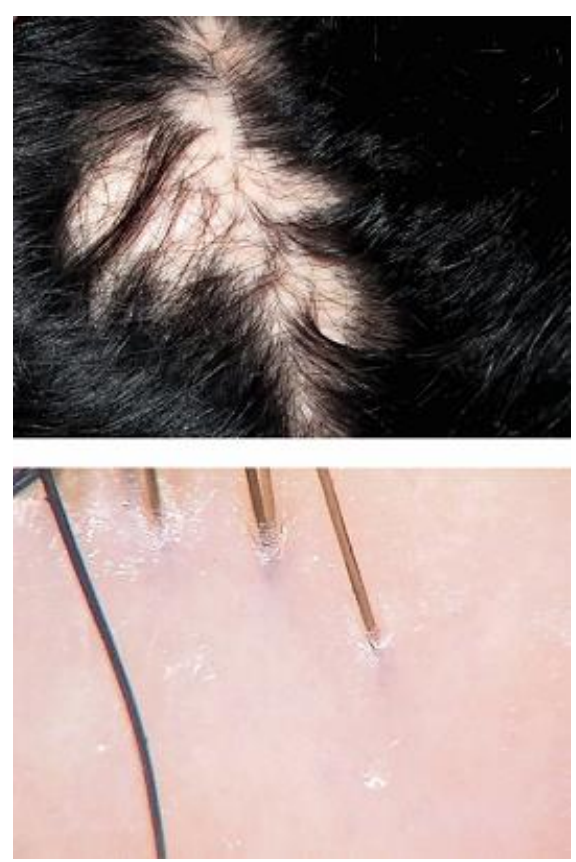

Figure 42. Smooth porcelain white skin to slight red tint with no follicular openings ${ }^{[39]}$

\section{Conclusion}

In conclusion, trichoscopy is a very useful, handy, and noninvasive tool in the armamentarium of dermatologist for diagnosis of hair and scalp disorders. Nonetheless, diagnosis cannot be made without a clinical case approach, available data and histological readings in some cases. All should complement each other.

\section{Conflict of interest}

The author declared no potential conflict of interest with respect to the research, authorship, and/or publication of this article.

\section{References}

1. Rakowska A. Trichoscopy (hair and scalp videodermoscopy) in the healthy female. Method standardization and norms for measurable parameters. J Dermatol Case Rep 2009; 3(1): 14-19. doi: 10.3315/jdcr.2008.1021.

2. Rudnicka L, Olszewska M, Rakowska A, Kowalska-Oledzka E, Slowinska M. Trichoscopy: A new method for diagnosing hair loss. J Drugs Dermatol 2008; 7(7): 651-654. 
3. Rudnicka L, Rakowska A, Olszewska M. Trichoscopy. How it may help the clinician. Dermatol Clin 2013; 31: 29-41. doi:10.1016/j.det.2012.08.011.

4. Kowalska-Oledzka E, Slowinska M, Rakowska A. Sensitivity and specificity of the trichoscopy. Indian J Dermatol Venereol Leprol 2012; 78(5): 636-637. doi: 10.4103/0378-6323.100591.

5. Rudnicka L, Olszewska M, Rakowska A, Slowinska M. Trichoscopy update 2011. J Dermatol Case Rep 2011; 5(4): 82-88. doi: 10.3315/jdcr.2011.1083.

6. Rudnicka L, Rakowska A, Kurzeja M, Olszewska M. Hair shafts in trichoscopy: Clues for diagnosis of hair and scalp diseases. Dermatol Clin 2013; 31(4): 695-708. doi: 10.1016/j.det.2013.06.007.

7. Tosti A, Duque-Estrada B. Dermoscopy in hair disorders. J Egypt Women Dermatol Soc 2009; 7(1): 1-4.

8. Romero J, Grimalt R. Trichoscopy: Essentials for the dermatologist. World J Dermatol 2015; 4(2): 63-68. doi: 10.5314/wjd.v4.i2.63.

9. Inui S. Trichoscopy: A new frontier for the diagnosis of hair diseases. Expert Rev Dermatol 2012; 7(5): 1-9. doi: 10.1586/edm.12.40.

10. Jain N, Doshi B, Khopkar U. Trichoscopy in alopecias: Diagnosis simplified. Int J Trichology 2013; 5(4): 170-178. doi: 10.4103/0974-7753.130385.

11. Herskovitz I, de Sousa ICVD, Tosti A. Vellus hairs in the frontal scalp in early female pattern hair loss. Int $\mathrm{J}$ Trichology 2013; 5(3): 118-120. doi: 10.4103/0974-7753.12 5601.

12. Bhamla SA, Dhurat RS, Saraogi PP. Is trichoscopy a reliable tool to diagnose early female pattern hair loss? Int J Trichology 2013; 5(3): 121-125. doi: 10.4103/0974 -7753.125603 .

13. Zhang X, Caulloo S, Zhao Y, Zhang B, Cai Z, et al. Female pattern hair loss: Clinico-laboratory findings and trichoscopy depending on disease severity. Int J Trichology 2012; 4(1): 23-28. doi: 10.4103/0974-7753.96082.

14. Rakowska A, Slowinska M, Kowalska-Oledzka E, Olszewska M, Rudnicka L. Dermoscopy in female androgenic alopecia: Method standardization and diagnostic criteria. Int J Trichology 2009; 1(2): 123-130. doi: 10.4103/0974-7753.58555.

15. Kibar M, Aktan Ş, Bilgin M. Scalp dermatoscopic findings in androgenetic alopecia and their relations with disease severity. Ann Dermatol 2014; 26(4): 478-484. doi: 10.5021/ad.2014.26.4.478.

16. Galliker NA, Trüeb RM. Value of trichoscopy versus trichogram for diagnosis of female androgenetic alopecia. Int J Trichology 2012; 4(1): 19-22. doi: 10.4103/0974-77 53.96080 .

17. Blume-Peytavi U, Blumeyer A, Tosti A, Finner A, Marmol V, et al. S1 guideline for diagnostic evaluation in androgenetic alopecia in men, women and adolescents. $\mathrm{Br}$ J Dermatol 2011; 164(1): 5-15. doi: 10.1111/j.1365-2133. 2010.10011.x.

18. Pedrosa AF, Morais P, Lisboa C, Azevedo F. The importance of trichoscopy in clinical practice. Dermatol Res Pract 2013; 2013: 986-970. doi: 10.1155/2013/986970.

19. de Moura LH, Duque-Estrada B, Abraham LS, Barcaui $\mathrm{CB}$, Sodre CT. Dermoscopy findings of alopecia areata in an African-American patient. J Dermatol Case Rep 2008; 27; 2(4): 52-54. doi: 10.3315/jdcr.2008.1020.

20. Kibar M, Aktan Ş, Lebe B, Bilgin M. Trichoscopic findings in alopecia areata and their relation to disease activity, severity and clinical subtype in Turkish patients. Australas J Dermatol 2015; 56(1): e1-e6. doi: 10.1111/ajd. 12102.

21. Molina L, Donati A, Valente NSY, Romiti R. Alopecia areata incognita. Clinics 2011; 66(3): 513-515. doi: 10.1590/S1807-59322011000300027.

22. Kibar M, Aktan Ş, Bilgin M. Dermoscopic findings in scalp psoriasis and seborrheic dermatitis; two new signs; signet ring vessel and hidden hair. Indian J Dermatol 2015; 60(1): 41-45. doi: 10.4103/0019-5154.147786.

23. Kim GW, Jung HJ, Ko HC, Kim MB, Lee WJ, et al. Dermoscopy can be useful in differentiating scalp psoriasis from seborrhoeic dermatitis. Br J Dermatol 2011; 164(3): 652-656. doi: 10.1111/j.1365-2133.2010.1018 $0 . x$.

24. El-Taweel AE, El-Esawy F, Abdel-Salam O. Different trichoscopic features of tinea capitis and alopecia areata in pediatric patients. Dermatol Res Pract 2014; 2014: 848763. doi: 10.1155/2014/848763.

25. Ankad BS, Naidu MV, Beergouder SL, Sujana L. Trichoscopy in trichotillomania: A useful diagnostic tool. Int J Trichology 2014; 6(4): 160-163. doi: 10.4103/0974-775 3.142856 .

26. Yorulmaz A, Artuz F, Erden O. A case of trichotillomania with recently defined trichoscopic findings. Int $\mathrm{J}$ Trichology 2014; 6(2): 77-79. doi: 10.4103/0974-7753.1385 97.

27. Mathew J. Trichoscopy as an aid in the diagnosis of trichotillomania. Int J Trichology 2012; 4(2): 101-102. doi: 10.4103/0974-7753.96903.

28. Thakur BK, Verma S, Raphael V, Khonglah Y. Extensive tonsure pattern trichotillomania-trichoscopy and histopathology aid to the diagnosis. Int J Trichology 2013; 5(4): 196-198. doi: 10.4103/0974-7753.130400.

29. Peralta L, Morais P. Photoletter to the Editor: The Friar Tuck sign in trichotillomania. J Dermatol Case Rep 2012; 30; 6(2): 63-64. doi: 10.3315/jdcr.2012.1103.

30. Rudnicka L, Olszewska M, Rakowska A. Tricholillomania and traction alopecia. In: Rudnicka L, Olszewska M, Rakowska A (editors). Atlas of Trichoscopy. London: Springer-Verlag; 2012. p. 257-275. doi: 10.1007/978-1-4 471-4486-1_20.

31. Gupta LK, Khare AK, Garg A, Mittal A. Congenital triangular alopecia: A close mimicker of alopecia areata. Int 
J Trichology 2011; 3(1): 40-41. doi: 10.4103/0974-7753. 82135.

32. de Campos JG, Oliveira CMPB, Romero SAR, Klein AP, de Melo Akel PB, et al. Use of dermoscopy in the diagnosis of temporal triangular alopecia. An Bras Dermatol 2015; 90(1): 123-125. doi: 10.1590/abd1806-4841.20153 639.

33. Ye Y, Zhang X, Zhao Y, Gong Y, Yang J, et al. The clinical and trichoscopic features of syphilitic alopecia. J Dermatol Case Rep 2014; 8(3): 78-80. doi: 10.3315/jdcr. 2014.1176.

34. Rakowska A, Slowinska M, Kowalska-Oledzka E, Warszawik O, Czuwara J, et al. Trichoscopy of cicatricial alopecia. J Drugs Dermatol 2012; 11(6): 753-758.

35. Kang H, Azolibani AA, Otberg N, Shapiro J. Lichen planopilaris. Dermatol Ther 2008; 21: 249-256. doi: 10.1111/j.1529-8019.2008.00206.x.

36. Ankad BS, Beergouder SL, Moodalgiri VM. Lichen planopilaris versus discoid lupus erythematosus: A trichoscopic perspective. Int J Trichology 2013; 5(4): 204-207. doi: 10.4103/0974-7753.130409.

37. Lanuti E, Miteva M, Romanelli P, Tosti A. Trichoscopy and histopathology of follicular keratotic plugs in scalp discoid lupus erythematosus. Int J Trichology 2012; 4(1): 36-38. doi: 10.4103/0974-7753.96087.

38. Toledo-Pastrana T, García Hernández MJ, Camacho Ma- rtínez FM. Perifollicular erythema as a trichoscopy sign of progression in frontal fibrosing alopecia. Int $\mathrm{J}$ Trichology 2013; 5(3): 151-153. doi: 10.4103/0974-7753.12 5616.

39. Fabris MR, Melo CP, Melo DF. Folliculitis decalvans: The use of dermatoscopy as an auxiliary tool in clinical diagnosis. An Bras Dermatol 2013; 88(5): 814-816. doi: 10.1590/abd1806-4841.20132129.

40. Rakowska A, Stefanato C, Czuwara J, Olszewska M, Rudnicka L. Folliculitis decalvans. In: Rudnicka L, Olszewska M, Rakowska A (editors). Atlas of Trichoscopy. London: Springer-Verlag; 2012. p. 319-329. doi: 10.10 07/978-1-4471-4486-1.

41. Rakowska A, Olszewska M, Czuwara J, KowalskaOledzka E, Rudnicka L. Dissecting cellulitis. In: Rudnicka L, Olszewska M, Rakowska A (editors). Atlas of Trichoscopy. London: Springer-Verlag; 2012. p. 331-337. doi: 10.1007/978-1-4471-4486-1_25.

42. Olszewska M, Radowska A, Rudnicka L. Pseudopelade of Brocq. In: Rudnicka L, Olszewska M, Rakowska A (editors). Atlas of Trichoscopy. London: Springer-Verlag; 2012. p. 339-340. doi: 10.1007/978-1-4471-4486-1_26.

43. BelleLASER [Internet]. 2015 [updated 2015; cited 2015 August 12]. Available from: http://www.bellelaser.com/en /clinic.htm 